\title{
Argon plasma coagulation and hyperbaric oxygen therapy in chronic radiation proctopathy, effectiveness and impact on tissue toxicity
}

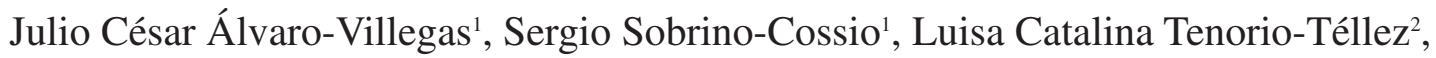 \\ José Guillermo de la Mora-Levy ${ }^{1}$, Angélica Hernández-Guerrero ${ }^{1}$, Juan Octavio Alonso-Lárraga ${ }^{1}$ \\ and Teresa Vela-Chávez ${ }^{3}$
}

Departments of ${ }^{1}$ Digestive Endoscopy, ${ }^{2}$ Radiotherapy, and ${ }^{3}$ Pathology. Instituto Nacional de Cancerología (INCan). Mexico City, Mexico

\begin{abstract}
Background: chronic radiation proctopathy $(\mathrm{CRP})$ is associated with recurrent rectal bleeding and transfusional requirements. Argon plasma coagulation (APC) and hyperbaric oxygen therapy (HOT) have been shown to be effective in the control of CRP. No prospective comparisons have been reported between these treatments.

Aim: the aim was to evaluate the effectiveness, safety and impact on tissue toxicity of APC compared to HOT in patients with CRP.

Material and methods: a prospective study for evaluating treatment response was conducted. Patients with cervical cancer and $\mathrm{CRP}$ with rectal bleeding were recruited. They had not received previous treatment. Collected data included: demographics, previous radiation dosage, duration and severity of rectal bleeding. Hemoglobin, transfusional requirements, and tissue toxicity (SOMA LENT questionnaire) at baseline and at 1,2, and 3 months follow up were recorded.

Results: thirty-one patients were included, 14 in the APC group and 17 in the HOT group. No response was noted in 13 and $18 \%$ of patients in the APC and HOT group respectively $(p=N S)$. At the 1 and 2 months follow-up, the APC group showed a significantly better response in terms of transfusional requirements (0.6 vs. 3.4 and 0.7 vs. 2.5) and tissue toxicity score (5.3 vs. 8.6 and $3.8 v s$. 7.248). After 3 months, both groups showed further improvement in all parameters without significant differences between them.

Conclusions: APC and HOT were effective, safe and decreased the tissue toxicity scores in patients with CRP. However, response rate was higher and faster in the APC group.
\end{abstract}

Álvaro-Villegas JC, Sobrino-Cossio S, Tenorio-Téllez LC, De la Mora-Levy JG, Hernández-Guerrero A, Alonso-Lárraga JO, Figueroa-Barojas $P$, Vela-Chávez T. Argon plasma coagulation and hyperbaric oxygen therapy in chronic radiation proctopathy, effectiveness and impact on tissue toxicity. Rev Esp Enferm Dig 2011; 103: 576-581.

Received: 04-03-10.

Accepted: 05-05-11.

Correspondence: Julio-Cesar Álvaro-Villegas. Department of Digestive Endoscopy. Instituto Nacional de Cancerología. Av. San Fernando \#22, Col. Sección XVI, Deleg. Tlalpan. 14080 México D.F., México.

e-mail: jc_alvarov@hotmail.com

\section{INTRODUCTION}

Radiotherapy exerts an accumulative, progressive, and unpredictable effect on tissue; doses $>50$ Gy to abdominal and/or pelvic tumors frequently cause chronic radiation proctopathy (CRP) $(1,2)$. Damage to the rectum is due to its vicinity and the fixed location within the pelvic radiation field $(3,4)$, while tolerance is inversely proportional to the volume of the radiated organ. Known predisposing factors for CRP include: age $>60$ years, comorbid disease (i.e. hypertension, diabetes and atherosclerosis), clinical stage and pelvic surgery. Concomitant use of chemotherapy also increases tissue damage $(4,5)$.

Radiation proctopathy can present acutely in $75-80 \%$ of patients and of these, $4-22 \%$ will progress to a chronic phase $(2,5-8)$. Chronic damage to the intestinal muscle wall decreases vascularity therefore inducing ischemia, submucosal fibrosis and ulceration of the superficial mucosa $(9,10)$. Local angiogenesis is a compensatory mechanism which reduces ischemia and tissular damage, but can cause rectal bleeding in about $3 \%$ of cases (2,7-10).

Rectal bleeding is usually persistent and recurrent episodes requiring multiple transfusions and hospitalization are frequent; this leads to a decreased quality of life (QOL). Many therapeutic modalities have been described, but none have been completely successful for the control of rectal bleeding in this setting $(7,11-17)$. At this time, there is no treatment that can be considered the "gold-standard", although argon plasma coagulation (APC) and hyperbaric oxygen therapy (HOT) have consistently demonstrated the best outcome with a mean efficacy of 86 and $56 \%$, respectively (11-16).

\section{OBJECTIVES}

The aim of our study was to compare the efficacy of APC vs. HOT for the control of rectal bleeding due to CRP, 
Table I. Chutkan Scale

\begin{tabular}{ll}
\hline & Chutkan Scale \\
\hline Grade 0 & No hemorrhage \\
Grade 1 & Blood on toilet paper or mixed with feces \\
Grade 2 & Drops of blood in the toilet \\
Grade 3 & Severe hemorrhage with expulsion of clots \\
Grade 4 & Hemorrhage that requires transfusion
\end{tabular}

and to evaluate tissue toxicity prior to and after treatment with either argon plasma or hyperbaric oxygen.

\section{MATERIALS AND METHODS}

A prospective study for evaluating treatment response was conducted in patients with CRP secondary to radiotherapy for cervical cancer treated at the Instituto Nacional de Cancerología in Mexico City. All patients had rectal bleeding due to CRP (grade 4 in Chutkan scale) (18) and all underwent full colonoscopy examination to rule out other causes of bleeding (i.e. local tumor activity or diverticulosis). Patients were excluded if a full endoscopic examination could not me performed (i.e. stricture, fistula) or if they were using anticoagulants, anti-platelet agents or nonsteroidal anti-inflammatory drugs (NSAIDs).

Patients were not randomized and they were sent for either APC (group A) or HOT (group B) by their primary care physician, according to resource availability at the time of referral. Specifically, the duration or severity of bleeding did not influence the treatment modality used.

The following data were collected: demographics, radiation dosage (Gy), duration and severity of rectal bleeding according to the Chutkan scale (Table I), transfusional requirements and endoscopic grade of proctopathy (19) (Table II), tissue toxicity was assessed using the SOMALENT (subjective, objective, management, analytic-late effects on normal tissue-taskforce) score. This tool provides a standardized and reproducible global assessment of the severity of radiation-induced complications (7).

The main end points for the study were hemoglobin level $(\mathrm{Hb})$, hematocrit (Hct), and results of the SOMA-LENT questionnaire at baseline and at 1,2 and 3 month followup, the number of sessions, percentage of treatment failures and development of complications. The severity of rectal bleeding and endoscopic grade of proctopathy at the end of follow-up were also recorded.

\section{Techniques}

\section{APC}

Non-contact coagulation was carried out using an ERBE ICC 200 coupled to an APC 300 unit (ERBE Elektromedi-
Table II. Endoscopic grading of proctopathy

\begin{tabular}{ll}
\hline & Endoscopic grade of Proctopathy \\
\hline Grade 0 & Normal mucosa \\
Grade 1 & $<10$ telangiectasias \\
Grade 2 & $>10$ telangiectasias \\
Grade 3 & Confluent lesions, active bleeding or friable \\
& mucosa
\end{tabular}

zin GmbH, Tubingen, Germany). A 2.3-mm-diameter Teflon ${ }^{\circledR}$ catheter was used at flow rate of $1.6 \mathrm{~L} / \mathrm{min}$, with a current power of $60-\mathrm{W}$. At this settings, vessels measuring up to $1.5 \mathrm{~mm}$ in diameter can be treated and tissue coagulation to a depth of 0.5-3 mm can be obtained (19). Argon was applied in non contact fashion to all endoscopically visible abnormal mucosa.

\section{HOT}

Patients were treated in a conventional hyperbaric chamber (SECHRIST 2800 Anaheim CA, USA) set at a pressure of 2-2.5 absolute atmospheres (ATM), with $100 \%$ hyperoxygenation in 90-min sessions. Each patient underwent at least 30 sessions as described in the literature (17) .

Results are presented as mean and standard deviation (SD) with $95 \%$ confidence interval $(95 \% \mathrm{CI})$. The $\chi^{2}$ test and one-tailed ANOVA was used to calculate differences between groups to a statistical significance of 0.05 .

The study protocol was approved by the Institutional Research and Ethics Committees.

\section{RESULTS}

A total of 31 patients with cervical cancer-associated CRP were recruited. Clinical and demographic data are shown in table III. Fourteen patients were included in group A (APC) and 17 in group B (HOT). Even though patients were not randomized to a specific treatment modality, there were no statistically significant differences between groups at baseline with regards to age $(59.3 \pm 12 v s .51 .9 \pm 12.5$ years; $\mathrm{p}=0.1)$, BMI $(26.4 \pm 4.3$ vs. $23.8 \pm 3.9 ; \mathrm{p}=0.08)$, total radiation dose $(81.1 \pm 9 v s .78 \pm 13.9 ; \mathrm{p}=0.5)$, duration of rectal bleeding $(9.6 \pm 5.1$ vs. $7.8 \pm 4.7$ months; $\mathrm{p}=$ $0.15)$, Hb levels $(9.9 \pm 2.3$ vs. $10.2 \pm 2.6 \mathrm{~g} / \mathrm{dl} ; p=0.69)$, number of transfusions (5.6 vs. 3.0 transfusions; $\mathrm{p}=0.17$ ), or SOMA-LENT score $(13.3 \pm 2.9 v s .12 .1 \pm 2.9 ; \mathrm{p}=0.31)$.

At 1 month follow up, no difference was observed between the two groups with regards to Hb levels (11.2 \pm 2 vs. $10.7 \pm 2.5 ; \mathrm{p}=0.54$ ); however, the number of transfusions $(0.6 \pm 1.1 v s .3 .4 \pm 3.9 ; \mathrm{p}=0.03)$ and tissue toxicity score $(5.3 \pm 3.4 v s .8 .6 \pm 3.7 ; \mathrm{p}=0.01)$ were significantly better for the APC group (Tables IV, V and Fig. 1). 
Table III. Clinical demographic data

\begin{tabular}{llll}
\hline & APC & HO & $p$ \\
\hline Age & & & \\
Mean & 59.3 & 51.9 & \\
$95 \% \mathrm{Cl}$ & $52.6-66$ & $45.8-57.9$ & 0.10 \\
SD & 12 & 12.5 & \\
BMI & & & \\
Mean & 26.4 & 23.8 & \\
95\% Cl & $24.2-28.7$ & $21.7-25.8$ & 0.08 \\
SD & 4.3 & 3.9 & \\
Rectal bleeding evolution & & & \\
time (months) & & & \\
Mean & 9.6 & 7.8 & \\
95\% & $7.05-11.2$ & $4.3-9.1$ & 0.15 \\
SD & 5.1 & 4.7 & \\
Total dose (Gy) & & & \\
Mean & 81.1 & 78.5 & \\
95\% Cl & $74.5-87.6$ & $72.6-84.5$ & 0.56 \\
SD & 9.0 & 13.9 & \\
\hline
\end{tabular}

At the second month follow up, the number of transfusions required by patients treated with HOT decreased, while there was no further change in the APC group $(0.7 \pm$ 1.3 vs. $2.5 \pm 3$ transfusions; $\mathrm{p}=0.04$ ), but there was still a statistically significant difference between groups in number of transfusions and tissue toxicity score $(3.8 \pm 2.9 v s .7 .2$ $\pm 4.8 ; p=0.03$ ). At the end of follow-up, there was continued improvement in both groups, with no statistically significant differences between them.

The mean number of session per patient was $3 \pm 1$ session for the APC group and $35 \pm 5$ sessions for the
Table V. Tissue toxicity measurements

\begin{tabular}{llll}
\hline Follow-up & \multicolumn{3}{c}{ SOMA-LENT (Tissue Toxicity) } \\
& APC & HO & $p$ \\
\hline Basal & & & \\
Mean & 13.3 & 12.2 & \\
$95 \% \mathrm{Cl}$ & $11.7-14.9$ & $10.7-13.6$ & 0.31 \\
SD & 2.9 & 2.9 & \\
1 month & & & \\
Mean & 5.3 & 8.6 & \\
95\% Cl & $3.3-7.2$ & $6.8-10.4$ & $0.01 *$ \\
SD & 3.5 & 3.7 & \\
2 months & & & \\
Mean & 3.8 & 7.2 & $0.03 *$ \\
$95 \% \mathrm{Cl}$ & $1.4-6.2$ & $5-9.4$ & \\
SD & 2.9 & 4.8 & \\
3 months & & & \\
Mean & 3 & 4.8 & \\
$95 \% \mathrm{Cl}$ & $1-4.9$ & $3-6.5$ & \\
SD & 3.5 & 3.5 & \\
\end{tabular}

HOT group. Complications presented in 5 patients in the APC group: two patients (18\%) presented with rectal pain after the first session which resolved after 2 weeks; and three patients (27\%) developed APC-associated rectal ulcers with good clinical response by the end of follow-up. Two patients in group A and 3 patients in group $\mathrm{B}$ had persistent rectal bleeding at the end of follow-up and were considered treatment failures. The two patients in group A were referred for HOT with clinical improvement in both, one of the patients in group B was treated with APC with good clinical response, and the two

Table IV. Measurements of clinical parameters

\begin{tabular}{|c|c|c|c|c|c|c|}
\hline \multirow[t]{2}{*}{ Follow-up } & \multicolumn{3}{|c|}{ Hemoglobin } & \multicolumn{3}{|c|}{ Number of transfusions } \\
\hline & $A P C$ & $\mathrm{HO}$ & $p$ & $A P C$ & $\mathrm{HO}$ & $p$ \\
\hline \multicolumn{7}{|l|}{ Baseline } \\
\hline Mean & 10.1 & 10.3 & & 4.8 & 3.8 & \\
\hline $95 \% \mathrm{Cl}$ & $8.8-11.4$ & $9.1-11.5$ & 0.8 & $1.7-7.9$ & $0.9-4.7$ & 0.17 \\
\hline SD & 2.1 & 2.6 & & 7.8 & 2.9 & \\
\hline \multicolumn{7}{|l|}{1 month } \\
\hline Mean & 11.2 & 10.7 & & 0.6 & 3.4 & \\
\hline $95 \% \mathrm{Cl}$ & $9.9-12.5$ & $9.5-11.8$ & 0.5 & $1.24-2.5$ & $1.7-5.1$ & 0.03 \\
\hline SD & 2 & 2.6 & & 1.12 & 3.93 & \\
\hline \multicolumn{7}{|l|}{2 months } \\
\hline Mean & 11.6 & 11.0 & & 0.74 & 2.49 & \\
\hline $95 \% \mathrm{Cl}$ & $10.3-12.8$ & 9.9-12.1 & 0.5 & $0.8-2.2$ & $1.2-3.9$ & 0.04 \\
\hline SD & 1.7 & 2.6 & & 1.3 & 3.0 & \\
\hline \multicolumn{7}{|l|}{3 months } \\
\hline Mean & 11.3 & 12 & & 0.6 & 0.8 & \\
\hline $95 \% \mathrm{Cl}$ & $10.2-12.5$ & 10.9-13 & 0.4 & $0.2-1.3$ & $0.25-1.6$ & 0.44 \\
\hline SD & 2.0 & 2.1 & & 0.9 & 1.2 & \\
\hline
\end{tabular}



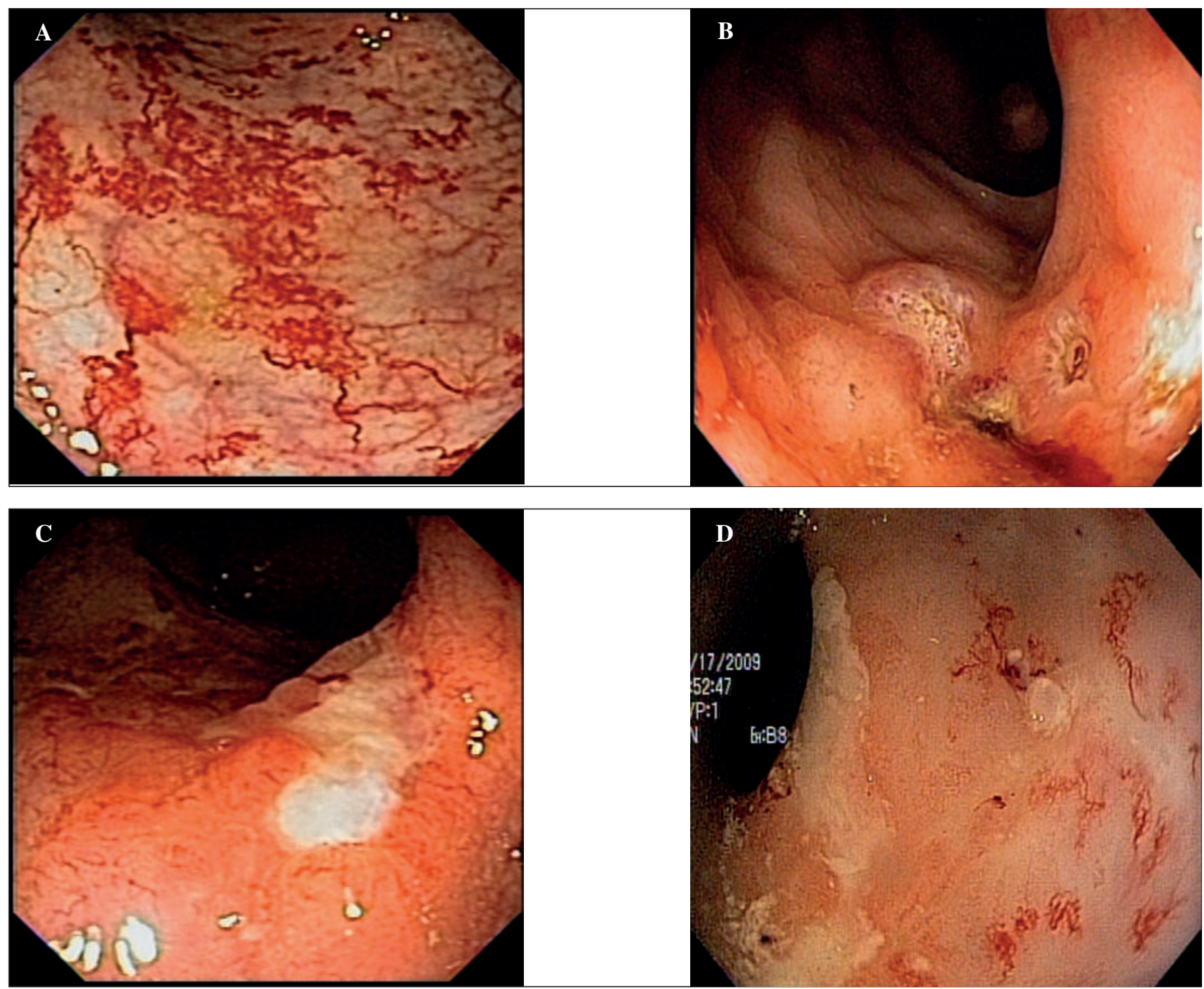

Fig. 1. Endoscopic response of chronic radiation proctopathy (CRP) to treatment with argon plasma coagulation (APC). Endoscopic image at baseline (A); 1 month (B); 2 month (C); and 3 month follow-up (D).

remaining patients had to undergo terminal colostomy for refractory bleeding.

\section{DISCUSSION}

Treatment with APC or HOT had similar results at the end of follow-up (control of rectal bleeding, reduction in number of transfusions, and improvement in the tissue toxicity), however, clinical response was faster with APC.

$\mathrm{CRP}$ is a complication of radiation treatment for pelvic malignancies. At our institution, it is a frequently encountered entity in patients treated for cervical cancer. Rectal bleeding is the most common clinical sign that can negatively impact the patient's QOL. There are no prospective studies comparing the effectiveness of APC to other treatment modalities (20).
Sebastian et al. (18), conducted a clinical trial without a control group $(n=25)$ in patients with CRP associated chronic rectal bleeding where they found a $76 \%$ efficacy for APC (1-4 sessions/patient), however they also included patients with prostate and bladder cancer, whose radiation field is different than for cervical cancer. They also found a significant decrease in the number transfusions required per patient.

Vargo (20) in a systematic review, reported a decrease in packed red blood cell requirements of up to $97.1 \%$ after two APC sessions. In our study, we observed a decrease in transfusion requirement from 6.0 units of packed red blood cells at baseline to $0.6 \pm 1.1$ (at 1 month), $0.7 \pm 1.3$ (at 2 months), and $0.5 \pm 0.8$ (at 3 months) follow-up ( $p=0.01$ ). The number of APC sessions required by each patient ranged from 1 to 4 . 
We observed a discrete improvement in Hb levels, however this did not reach statistical significance $(95 \%$ CI, 8.911.2 vs. 95\% CI, 10.2-2.5; $\mathrm{p}=0.13$ ). Also, the degree of rectal bleeding and the SOMA-LENT toxicity score decreased significantly, from 13.3 (95\% CI, 11.5-15) before treatment to $3.0(95 \% \mathrm{CI}, 1.2-4.8)(\mathrm{p}=0.0001)$ at 3 month of follow-up.

Villavicencio et al. (14) reported a 91\% efficacy in patients with recurrent CRP-associated rectal bleeding after APC application (1-1.7 sessions). Complications were present in $14 \%$ of the cases (pain, tenesmus, and diarrhea). Similarly, in our study, two patients (18\%) presented with rectal pain after the first session which resolved after 2 weeks and three patients (27\%) developed APC-associated rectal ulcers with good clinical response by the end of follow-up. Ravizza et al. (13) reported control of bleeding in $88.8 \%$ of patients after the first APC application; however, the majority of patients presented complications such as rectal ulcers and persistent pain that lasted on average 2.5 months. The presence of complications was probably due to the fact that they treated extensive areas of mucosa in two sessions. In order to decrease the number of complications they modified the current and gas flow from 60 to $40 \mathrm{~W}$ and 3 to $2 \mathrm{~L} / \mathrm{min}$, respectively. In contrast, a similar power setting $(60 \mathrm{~W})$ with a lower gas flow was used (1.6$\mathrm{L} / \mathrm{min}$ ) in our study and extensive areas of mucosa were never treated in a single session, therefore a greater number of APC sessions were performed $(3 \pm 1$ sessions per patient). Of note, the size of the area to be treated in each session has not been reported in the literature or standardized therefore comparisons with other previously published studies is not possible.

In contrast, Silva et al. (21) reported adequate clinical response without any complications in 28 patients with anemia and recurrent rectal bleeding treated with two APC sessions. The development of complications, such as rectal pain and mucosal lesions is probably due to several factors, such as degree of CRP, the technique utilized for treatment, the current flow settings, and the extent of the area treated at a single session which to our knowledge has not been studied specifically.

Clarke et al. (7) carried out a randomized multicenter study in 120 patients with persistent hematochezia without response to medical treatment after 3 months. They reported an improvement in the tissue toxicity score after treatment in patients treated with $100 \%$ HOT, after 30 sessions $(\mathrm{p}=0.0019)$. In our series, the use of $100 \%$ HOT lead to a significant improvement in tissue toxicity score from $12.1 \pm 2.9(95 \% \mathrm{CI}, 10.3-14)$ at baseline to $8.6 \pm 3.7(95 \%$ CI, 6.7-10.4) at 1 month, $7.2 \pm 4.8(95 \% \mathrm{CI}$; 5.4-9.1) at 2 months, and $4.7 \pm 3.5(95 \% \mathrm{CI}, 2.9-6.1)$ at 3 months ( $\mathrm{p}=$ 0.001 ).

Kitta et al. (22) published a small case series $(n=4)$ of patients treated with HOT for refractory rectal bleeding (30-60 sessions) with one patient requiring blood transfusions, and two patients having clinical improvement after 3 months of treatment. In our study, 3 out of 17 patients treated with HOT persisted with rectal bleeding and were considered treatment failures. They were referred for other treatments (APC, surgery). The predictive factors for treatment failure are unknown.

Finally, proctopathy-associated rectal bleeding is a challenging disorder. A significant number of patients will persist with symptoms and poor QOL. It is necessary to evaluate treatment response, compare different treatment options, increase the sample size and improve patient selection in order to obtain more information regarding the management of these patients.

\section{CONCLUSIONS}

Treatment with APC or HOT is similar with regards to rectal bleeding, transfusion requirements and improvement in the tissue toxicity. However, clinical response was faster with APC. A significant number of patients will persist with rectal bleeding and poor QOL despite treatment with any of these modalities. Combination treatment should be studied in future studies.

\section{REFERENCES}

1. Kinsella TJ, Bloomer WD. Tolerance of the intestine to radiation therapy. Surg Gynecol Obstet 1980;151:273-84.

2. Cho KH, Chung KKL, Levitt SH. Proctitis after conventional external radiation therapy for prostate cancer: importance of minimizing posterior rectal dose. Radiology 1995;195:699-703.

3. Saclarides TJ. Radiation injuries of the gastrointestinal tract. Surg Clin North Am 1997;77:261-8.

4. Babb RR, Radiation proctitis: a review. Am J Gastroenterol 1996; 91:1309-11.

5. Anseline PF, Lavery IC, Fazio VW, Jagelman DG. Weakley FL. Radiation injury of the rectum, evaluation of surgical treatment. Ann Surg 1981;194:716-24.

6. Coia LR, Myerson RJ, Tepper JE, Late effects of radiation therapy on the gastrointestinal tract. Int J Radiat Oncol Biol Phys 1995; 31:121336.

7. Clarke R, Tenorio L, James R, Hussey J. Hyperbaric oxygen treatment of chronic refractory radiation proctitis: a randomized and control led double blind crossover trial with long term follow up Int J Radiat Oncol Biol Phys 2008;72:134-43.

8. Friedland S, Benaron D, Maxim P. Absence of ischemia in telangiectasias of chronic radiation proctopathy, Endoscopy 2006; 38:488-92.

9. Haselton PS, Carr N, Schofield PF. Vascular changes in radiation bowel disease. Histopathology 1985; 9:517-34.

10. Rmali KA, Puntis CA, Jiang WG. Tumour associated angiogenesis in human colorectal cancer. Int J Colorectal Dis 2007;9:3-14.

11. Prachi L, Naresh B, Anil B. Management of chronic hemorrhagic radiation proctitis. Asian Pac J Clin Oncol 2007;3:19-29.

12. Lee J. Radiation proctitis- a niche for the argon plasma coagulator, Gastrointest Endosc 2002;56:779-81.

13. Ravizza D, Fiori G, Trovato C, Crosta C. Frequency and outcomes of rectal ulcers during argon plasma coagulation for chronic radiationinduced proctopathy. Gastrointest Endosc 2003;57:519-25.

14. Villavicencio R, Rex D, Rahmani E. Efficacy and complications of argon plasma coagulation for hematochezia related to radiation proctopathy. Gastrointest Endosc 2002;55:70-4.

15. Woo TCS, Joseph D, Oxer H. Hyperbaric oxygen treatment for radiation proctitis. Int J Radiat Oncol Biol Phys 1997;38:619-22.

16. Warren DC, Feehan P, Slade JB, Cianci PE. Chronic radiation proctitis treated with hyperbaric oxygen. Undersea Hyper Med 1997;24:181-4. 
17. Hong J, Park W, Ehrenpreis D. Current therapeutic option for radiation proctopathy (Review). Aliment Pharmacol Ther 2001;15:1253-62.

18. Sebastian S, O'Connor H, O'Morain C, Buckley M. Argon plasma coagulation as first-line treatment for chronic radiation proctopathy. J Gastroenterol Hepatol 2004;19:1169-73.

19. Chi KD, Ehrenpreis ED, Jani AB. Accuracy and reliability of the endoscopic classification of chronic radiation-induced proctopathy using a novel grading method. J Clin Gastroenterol 2005;39:42-6.
20. Vargo J. Clinical applications of the argon plasma coagulator. Gastrointest Endosc 2004;59:81-8.

21. Silva RA, Correia AJ, Dias LM, Viana HL, Viana RL. Argon plasma coagulation therapy for hemorrhagic radiation proctosigmoiditis. Gastrointest Endosc 1999;50:221-4.

22. Kitta T, Shinohara H, Shirato H, Otsuka H. The treatment of chronic radiation proctitis with hyperbaric oxygen in patients with prostate cancer. BJU Int 2000;85:372-4. 